\title{
Interplate coupling and seismotectonics under the fore-arc regions of Japan*
}

\author{
Zhi Wang * \\ State Key Laboratory of Oil and Gas Reservoir Geology and Exploitation, \\ Chengdu University of Technology, Chengdu 610059, China
}

\begin{abstract}
Three-dimensional P- and S-wave velocities $\left(v_{\mathrm{P}}, v_{\mathrm{S}}\right)$, Poisson's ratio $(\sigma)$, crack-density $(\varepsilon)$ and bulk-sound velocity $\left(v_{\phi}\right)$ structures along the slab upper boundary beneath the fore-arc regions were determined using a large number of high-quality P-wave and S-wave arrival times from both onshore and offshore earthquakes in Japan. The velocity and Poisson's ratio images provide a compelling evidence for a highly hydrated and serpentinized fore-arc mantle and fluid-bearing anomalous low velocity and high Poisson's ratio associated with slab dehydration under the fore-arc areas. Most great thrust earthquakes $(M>7.5)$ occurred at or close to the high-velocity areas along the slab interface under the fore-arc areas, suggesting strong interplate coupling (asperities) with slab subduction. On the other hand, prominent low-velocity anomalies were revealed along the slab upper boundary, which may reflect weak coupled or decoupled patches (aseismicity) of the plates due to serpentinization of the fore-arc mantle wedge. The crack-density and bulk-sound velocity images, calculated from the corresponding velocity models, indicate that the interplate coupling in northeastern Japan is different from that under central and southwestern Japan owing to differences between the tectonic backgrounds of the subduction system, such as the geological age, thermal regime and dipping angle of the oceanic plates. A comparison between fluid-related anomalies of Japan, Cascadia, Chile, and Costa Rica subduction zones suggests that seismic mantle may be common in fore-arc settings and these reflect similar 3-D seismic structures relatively to fluid liberating processes. We consider that the fluid-bearing anomalies along the interface of the subducting slab, attributing to processes such as slab dehydration and serpentinization of the fore-arc mantle, are mainly contributed to the interplate coupling and the repeated generation of the great thrust earthquakes under the fore-arc regions in Japan.
\end{abstract}

Key words: sP depth phase, master-event location (MEL); interplate coupling; seismotectonics CLC number: P315.2 Document code: A

\section{Introduction}

The Islands of Japan is a distinct region characterized by the presence of three main tectonic plates: the Pacific plate, the Eurasian plate and the Philippine Sea (PHS) plate (Figure 1). The Pacific plate subducts WNW under the PHS plate and the Eurasian plates with a $\sim 30^{\circ}$ angle of dip and a rate of $\sim 10 \mathrm{~cm} / \mathrm{a}$ from the Japan-Kuril Trench in Northeastern Japan (Zhao et al., 1992; Wang and Zhao, 2005). The PHS plate is subducting to the WNW under the Eurasian plate at a relative rate of $\sim 5.5 \mathrm{~cm} / \mathrm{a}$ from the Nankai Trough in Southwestern Japan (Wang and Zhao, 2006a; Long and Van der Hilst, 2006; Zhao et al., 2007, 2009). In central

\footnotetext{
* Received 28 June 2010; accepted in revised form 10 October 2010; published 10 December 2010 .

• Corresponding author. e-mail: mike-wang@sohu.com

(C) The Seismological Society of China and Springer-Verlag Berlin Heidelberg 2010
}

Japan, the PHS plate is sandwiched by the overlying Eurasian plate and the underlying Pacific slab (Ishida, 1992; Wang and Zhao, 2006b). The fore-arc regions of Hokkaido, Northeastern Japan, Kanto district and Kyushu in Japan are the sites of important processes associated with the subduction of the Pacific and PHS plates, including serpentinization of the fore-arc mantle, repeated genesis of megathrust earthquakes, slab dehydration and the interplate coupling. Many previous studies were conducted to investigate the structural heterogeneities and their implications for the seismotectonics and arc volcanisms under the land areas of Japan (e.g., Zhao et al., 1992; Zhang et al., 2004; Nakajima et al., 2002; Nakajima and Hasegawa, 2007). Few studies of the structural heterogeneities under the fore-arc areas in the Pacific Ocean and the Philippine Sea were done because the offshore earthquakes are poorly located by the routine procedure of the seismic network on the land areas 


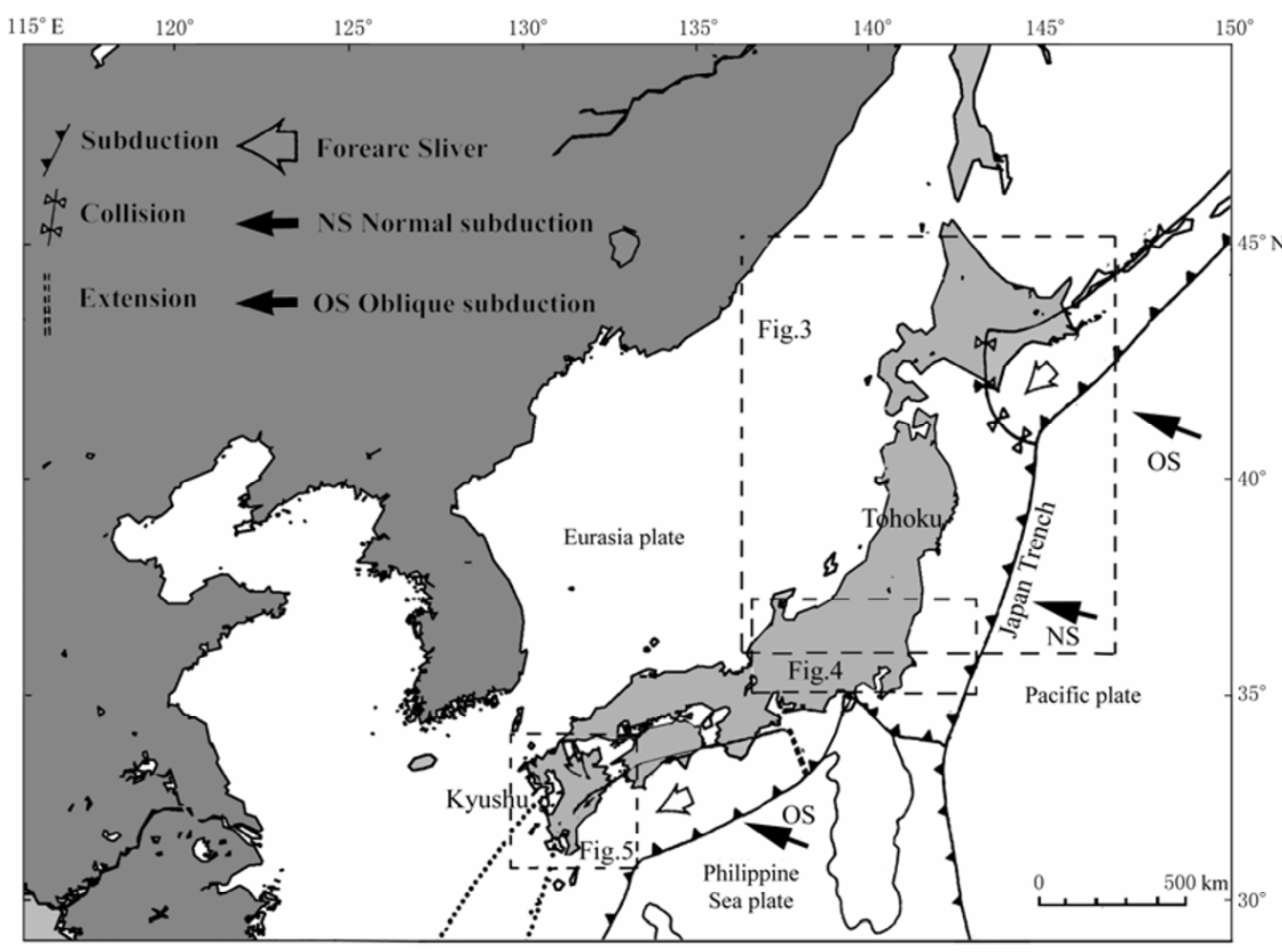

Figure 1 Map showing the tectonic framework around the Islands of Japan (Modified from Kamata and Kodama, 1999). Curved lines show the trenches that represent the major plate boundaries in Japan. Three boxes show the study regions, the Northeastern Japan (Figure 3), the Kanto district in Central Japan (Figure 4) and Kyushu in Southwestern Japan (Figure 5).

owing to few seismic stations located there. However, more great earthquakes occurred under the offshore areas than onshore. The frequent occurrence of great thrust earthquakes in the fore-arc regions has caused widespread damage to the coastal areas through strong shakings and tsunamis. The spatial distribution of the megathrust earthquakes indicates significant variations under the fore-arc areas along the Islands of Japan (Kawakatsu and Seno, 1983; Hasegawa et al., 1994; Wang and Zhao, 2005). We consider that the seismicity and interplate coupling or decoupling along the slab's upper boundary might be correlated with the structural heterogeneities. Therefore, information on the detailed velocity structures together with other physical parameters along the upper boundary of the subducting slab in the fore-arc regions is crucial for a better understanding of the initiation of the interplate coupling, the rupture nucleation of destructive interplate earthquakes and the slab dehydration. However, such information is scanty because the fore-arc areas are generally covered under oceans, and consequently there are few seismic stations available there to record the offshore earthquakes.

Umino et al. (1995) detected the sP depth phase in the offshore area of Northeastern Japan, and then they relocated 690 small offshore earthquakes using theoretical sP-P travel times calculated with a two-dimensional ray-tracing method. In their study only the focal depths of the offshore earthquakes were determined, while the epicenters were fixed. Mishra et al. (2003) and Zhao et al. $(2002,2007,2009)$ applied the same procedure as the previous study to have relocated another 92 offshore earthquakes and then they estimated the velocity structures under the offshore region in Tohoku. However, the seafloor topography of the Pacific Ocean, which has strong influence on the calculation of the ray paths and the travel times, was not considered in their studies. This is because the depth of the seafloor varies from tens to thousands of meters under the offshore regions from the trench to the eastern coast line of Japan.

Based on the above reasons, we presented a new method to find the bounce point of the sP depth phase using a three-dimensional perturbation method and then relocated 385 offshore earthquakes including both focal depths and epicenters under the offshore regions of Northeast Japan and Hokkaido (Wang and Zhao, 2005). Meanwhile, the influence of the seafloor topography 
was considered for the first time in their study. Furthermore, taking advantage of a new hypocenter location techniques (Waldhauser and Ellsworth, 2000; Wang and Zhao, 2005), we presented an effective hypocenter location method (Master-Event location: MEL) for the offshore earthquakes, outside the areas covered by the seismic networks (Wang and Zhao, 2006a, b, c). This method makes use of the sP depth phase combined with the extended double-difference location method. To demonstrate the effectiveness of the MEL method, they applied it to both a real data set in Central Japan (Wang and Zhao, 2006b) and a synthetic data set in Southwestern Japan (Wang and Zhao, 2006a). The testing results showed that the hypocenters of the offshore earthquakes that were relocated with the MEL method are consistent with those determined by using the arrivals recorded by the offshore stations.

In this study the Poisson's ratio $(\sigma)$, crack-density $(\varepsilon)$ and bulk-sound velocity $\left(v_{\phi}\right)$ images were calculated from the corresponding velocity models. The calculated parameters are less reliable than the inverted velocity structures. The velocity images and the calculated physical parameters revealed not only the common consensus on interpretational framework of seismic tomography but also the difference of the structural heterogeneities under the fore-arc regions from Northeastern to Southwestern Japan. Noted that the calculated crack-density images are reliable feature at shallow depth under the fore-arc region but would be unreliable at deep depth under the mantle wedge. Here I only discuss the crack-density structures beneath the fore-arc region. Those observations suggest that most of the seismological processes, such as the slab dehydration, interplate coupling and the genesis of megathrust earthquakes, are mainly attributed to the subduction conditions, for instance, the geological ages, the dipping angle and temperature of the subducting slab as well as the convergence of the Pacific and the PHS plates.

\section{Data and method}

The high-resolution 3-D velocity models shown in this study (Figures 3-5) were calculated using a combined data set including two groups of earthquakes (Wang and Zhao, 2005, 2006a, b). One group consists of 27388 shallow and intermediate-depth earthquakes (depth $<200 \mathrm{~km}$ ) that occurred beneath the land areas of Japan. These events were located within the seismic network and so they have reliable hypocentral locations with errors smaller than $0.5 \mathrm{~km}$ in epicentral location and $2.0 \mathrm{~km}$ in depth. The other group includes 3728 offshore earthquakes at depths of $10-80 \mathrm{~km}$ within the fore-arc regions of Japan from Hokkaido to Kyushu. These offshore events have been relocated using the sP depth-phases that were identified from the three-component seismograms recorded by the Hi-net using the MEL method (Wang and Zhao, 2006a, b). Figure 2 shows the ray path of the sP depth phase and four examples of the seismograms generated from the offshore earthquakes in Japan. Hypocenters of the offshore events are well constrained by the use of sP depth phase data and the MEL method. Their mislocation errors are generally smaller than $3.0 \mathrm{~km}$ in focal depth; comparable to that of the earthquakes occurred within the seismic network (Wang and Zhao, 2006b). A total of 645018 P-wave, 615943 S-wave and 7643 sP depth phase arrivals from the selected 27388 land earthquakes and 3728 offshore earthquakes have been collected. The picking accuracy is $0.05-0.1 \mathrm{~s}$ for $\mathrm{P}$-wave data, $0.05-0.2 \mathrm{~s}$ for $\mathrm{S}$-wave data, and $0.1-0.8 \mathrm{~s}$ for the $\mathrm{sP}$ depth phase data.

The regional tomography method (Zhao et al., 1992) was applied to the arrival times from the well relocated earthquakes to determine the 3-D velocity images (Wang and Zhao, 2005, 2006a, b). We then applied the crack theory (O'Connell and Budiansky, 1974; Mishra et al., 2003; Wang et al., 2006, 2009) and method of the bulk-sound velocity (Kennett et al., 1998; Kennett and Summins, 2005; Schmid et al., 2006; Wang et al., 2008) to calculating the crack-density and bulk-sound velocity structures from the tomography velocity models along the slab upper boundary, respectively. Estimated crack parameter together with the Poisson's ratio and bulk-sound velocity images can significantly improve our understanding of structural heterogeneities under the fore-arc regions of Japan.

\section{Discussion}

\subsection{Structural heterogeneities and seismotectonics}

Figures 3, 4 and 5 show the plan views of P- and S-wave velocity structures together with the Poisson's ratio, crack-density and bulk-sound velocity images for a two-km-thick layer right above the upper boundaries of the Pacific plate (Figures 3 and 4) and the PHS slab (Figure 5). The spatial distributions and perturbations of $\mathrm{P}$ - and S-wave velocity anomalies are similar to one another, although the amplitudes of the P-wave velocity 


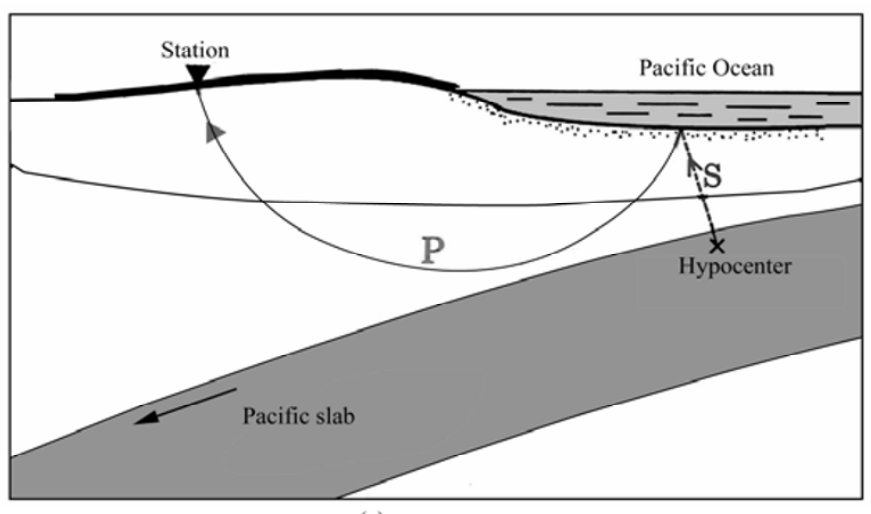

(a)

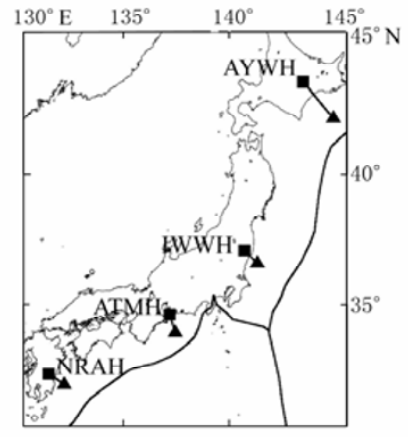

(b)

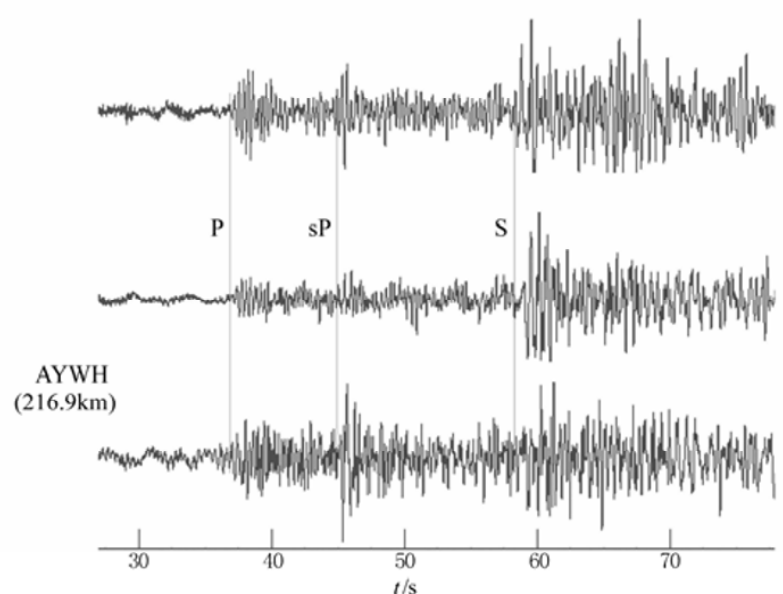

GMT $2004-05-18,03 \mathrm{~h} 48 \mathrm{~min} ; 42.02^{\circ} \mathrm{N}, 144.85^{\circ} \mathrm{E}, M 3.0$

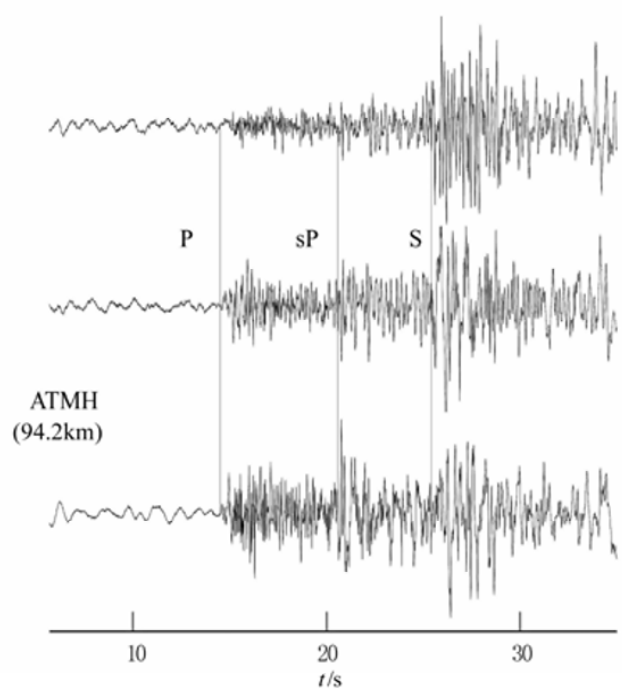

GMT $2003-01-22,20 \mathrm{~h} 12 \mathrm{~min}: 33.85^{\circ} \mathrm{N}, 137.26^{\circ} \mathrm{E}, M 2.7$

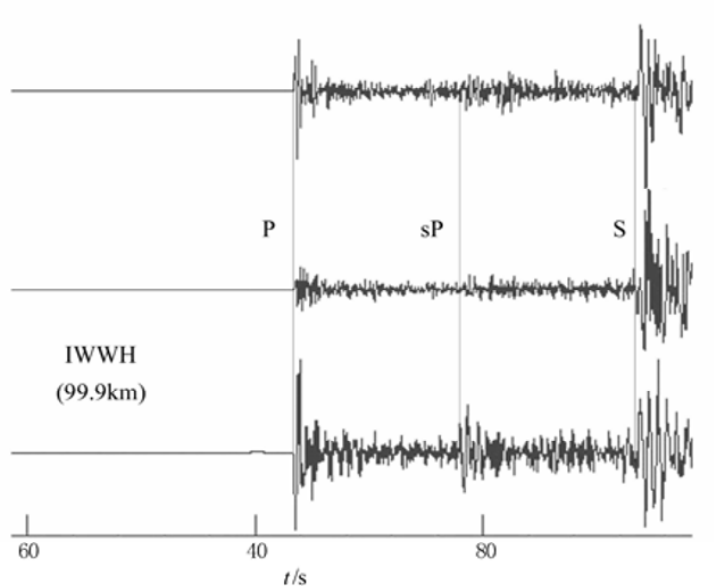

GMT $2004-04-23,05 \mathrm{~h} 37 \mathrm{~min} ; 37.60^{\circ} \mathrm{N}, 141.20^{\circ} \mathrm{E}, M 3.7$

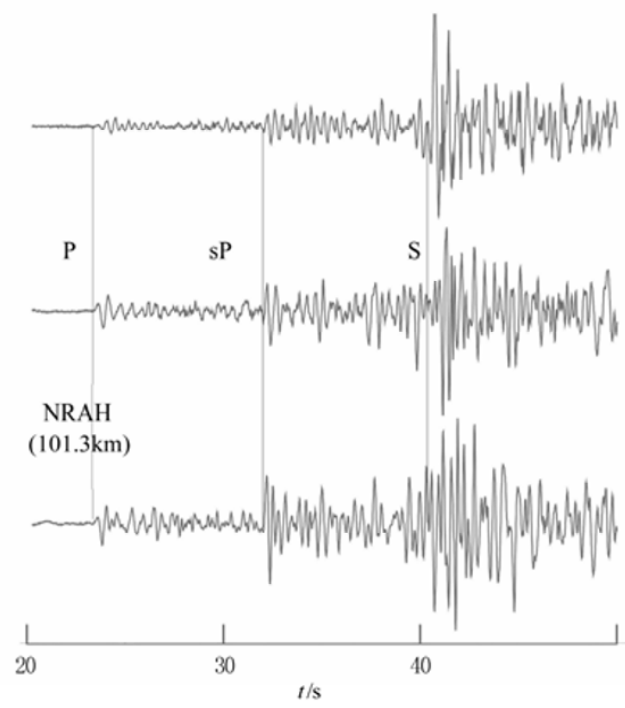

GMT $2004-07-15,22 \mathrm{~h} 42 \min : 31.74^{\circ} \mathrm{N}, 131.93^{\circ} \mathrm{E}, M 3.3$

(c)

Figure 2 (a) Schematic map showing the ray path of the sP depth phase from an offshore earthquake to the land-based station. (b) Locations of the offshore events and the stations that recorded the arrival times from the offshore events. (c) Four examples of the three-component seismograms that were generated from the offshore events recorded by the land-based stations. From the left to right in each seismogram, three vertical lines indicate the arrivals of P-wave, sP-depth phase and S-wave arrival times, respectively. The epicentral distance of the corresponding stations (alphabetical codes) are shown of the left of each seismogram. The hypocentral parameters are listed above each seismogram. 



Figure 3 P-wave, S-wave, Poisson's ratio and crack-density as well as bulk sound velocity images along the upper boundary of the subducting Pacific slab in Northeastern Japan. The location of the plan views along the line shown in the insert map. Blue color denotes high velocity and red color indicates low velocity. Opened circles represent epicenters of large historic interplate earthquakes $(M>6.0)$ occurred between 830.A.D and 2001. Red triangles denote active volcanoes along the Kuril-Northeastern Japan arc. The contour lines show distribution of rupture areas of the great earthquakes (epicenters as red circles, $M>7.5$ ) estimated by Nagai et al. (2001). The color scales of the velocity, Poisson's ratio, crack-density and bulk sound velocity are shown horizontally.

anomalies are less than the S-wave under Northeastern Japan (Figure 3) and the Kanto district (Figure 4). However, this feature of the velocity anomalies is not observed under the Kyushu subduction zone (Figure 5). Beneath the offshore area in Northeastern Japan, two Pand S-wave low-velocity areas with high Poisson's ratio and high crack-density anomalies are imaged (Figure 3). Similarly, high $v_{\mathrm{P}} / v_{\mathrm{S}}$ zones above the subducting Pacific slab were revealed by double-difference tomography in northern Honshu, which was interpreted as the serpentine dehydration (Zhang et al., 2004). The features of the structural heterogeneities under the offshore region are consistent with the previous studies (Iio et al., 2002; Zhao et al., 2002; Mishra et al., 2003). Two slow velocity zones $\left(39^{\circ} \mathrm{N}-41.2^{\circ} \mathrm{N}\right.$ and $42.0^{\circ} \mathrm{N}-43.0^{\circ} \mathrm{N}$ ) (with low-velocity perturbations of $\sim 2 \%-6 \%$ for $\mathrm{P}$ wave and $4 \%-6 \%$ for $\mathrm{S}$ wave) are imaged clearly, where no great interplate earthquakes $(M>7.5)$ had occurred. The low-velocity anomalies are consistent with a proposed seismic moment-release gap (Kawasaki et al., 2001). Strong heterogeneity is revealed at the shallow depths above the subducting slab under the Kanto district (Figure 4). Similar features are observed from the inverted velocity structures in the Kyushu subduction zone. Those low-velocity anomalies could be caused by fluids that are released upwards to the surface by porosity collapse 

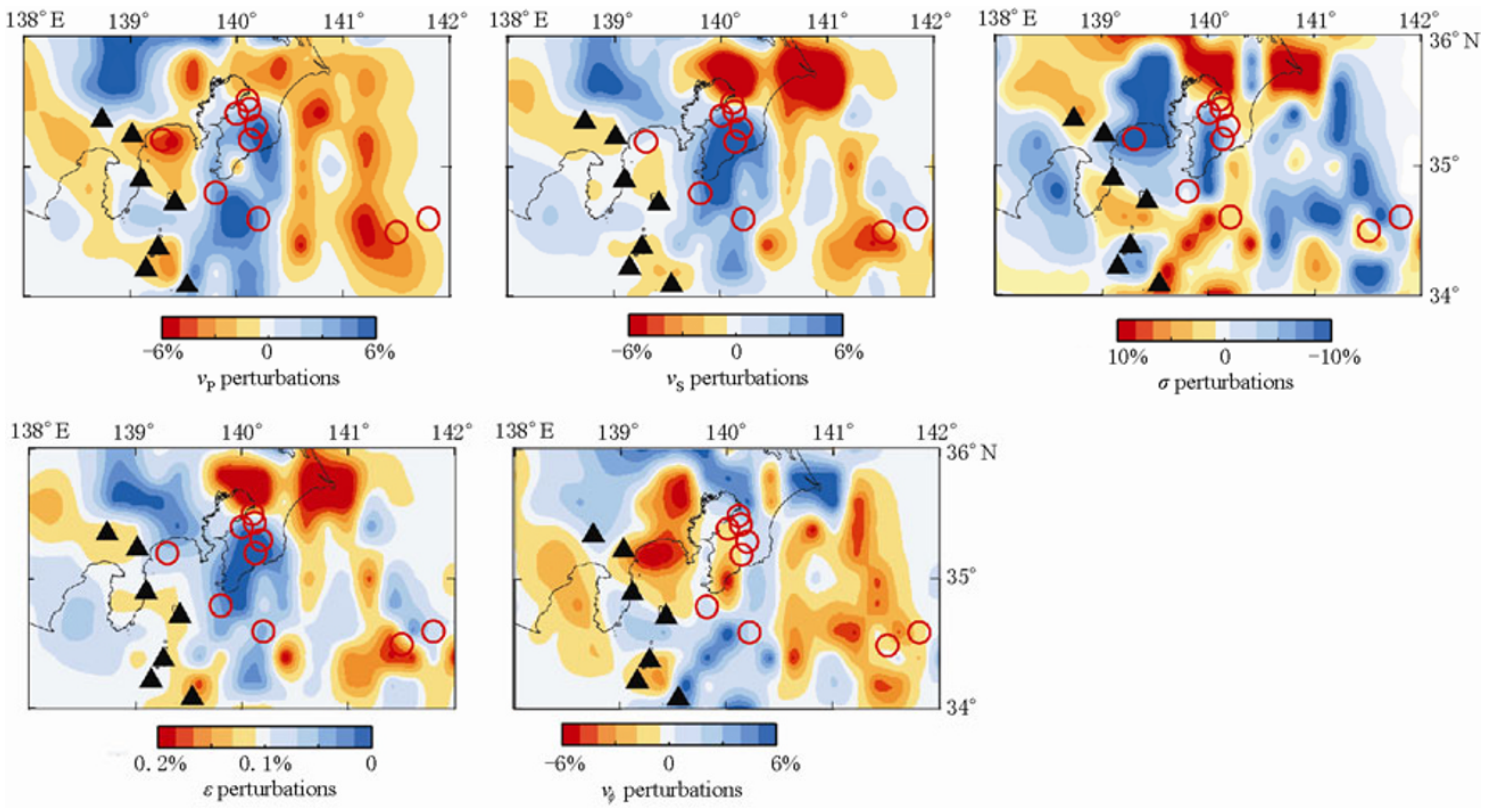

Figure 4 P-wave, S-wave, Poisson's ratio, crack-density and bulk sound velocity images along the upper boundary of the subducting Pacific slab under Central Japan. Black triangles indicate active volcanoes and red circles denote the large thrust earthquakes ( $M>6.0)$ occurred during the period from 1923 to 1998 (Utsu, 1999). The color scales of the velocity, Poisson's ratio, crack-density and bulk sound velocity are shown at the bottom of each map.

or dehydration of the subducting sediments and the oceanic crust.

Many large earthquakes occurred between the subducting slab and the overriding continental plate along the interplate thrust zones in Hokkaido, Tohoku, Kanto district and Kyushu of Japan, for example, the 1936 Miyagi earthquake (M7.5), the 1994 Shanriku earthquake (M7.5) and the 2003 Tokachi-oki earthquake (M8.0) in Northeast Japan, the 1941 (M7.2) and 1968 (M7.5) and 1984 (M7.1) Hyuga-nada earthquakes in Kyushu. Figures 3, 4 and 5 demonstrate that more than $92 \%$ of the great interplate earthquakes $(M \geq 7.5)$ occurred around the low-velocity zones, while only a few large interplate earthquakes (M6.0-6.5) occurred in the low-velocity areas, which inferred the existence of weakly coupled patches along the upper boundary of the subducting PHS slab. Similar features were revealed under the fore-arc area of Northeastern Japan (Zhao et al., 2002; Mishra et al., 2003), which may reflect a common feature on the spatial distribution of thrust earthquakes and the structural heterogeneities in subduction zones. The mechanism of large thrust earthquakes (Figure 6) calculated by using the Harvard CMT and Hi-Net catalogs shows similar generated mechanism of the large interplate earthquakes in the Northeast Japan and Kyushu but the Kanto district where the Philippine
Sea plate is sandwiched by the underlying Pacific and the overlying Eurasian plates (Figure 1). For the subducting slab, the down-dip limit of the great thrust earthquakes often corresponded to the intersection of the thrust with the fore-arc mantle (Springer and Forster, 1998), which might be explained by aseismic hydrous minerals, such as serpentinite, which are present in the fore-arc mantle wedge and exhibit stable sliding (Peacock and Hyndman, 1999, Oleskevich et al., 1999, Hyndman and Peacock, 2003). Our results show that these interplate thrust earthquakes were located in areas with seismic velocities that are higher than those of their surrounding areas (Figures 3, 4 and 5), which might reflect the futures of strong-coupled asperities.

We consider that one possible explanation for the spatial distribution of the large interplate earthquakes is that the lateral heterogeneities, including strong coupling sections or asperities and weak coupled or decoupled patches located along the upper slab boundary, might control the degree and spatial extent of the interplate seismic coupling and the rupture nucleation of the interplate earthquakes. The occurrence of slow and ultra-slow great interplate earthquakes that ruptured the oceanic lithosphere from the seafloor to a depth of several tens of kilometers (Kanamori, 1971; Kawasaki et al., 2001) may be related to the fluid contents along the slab 

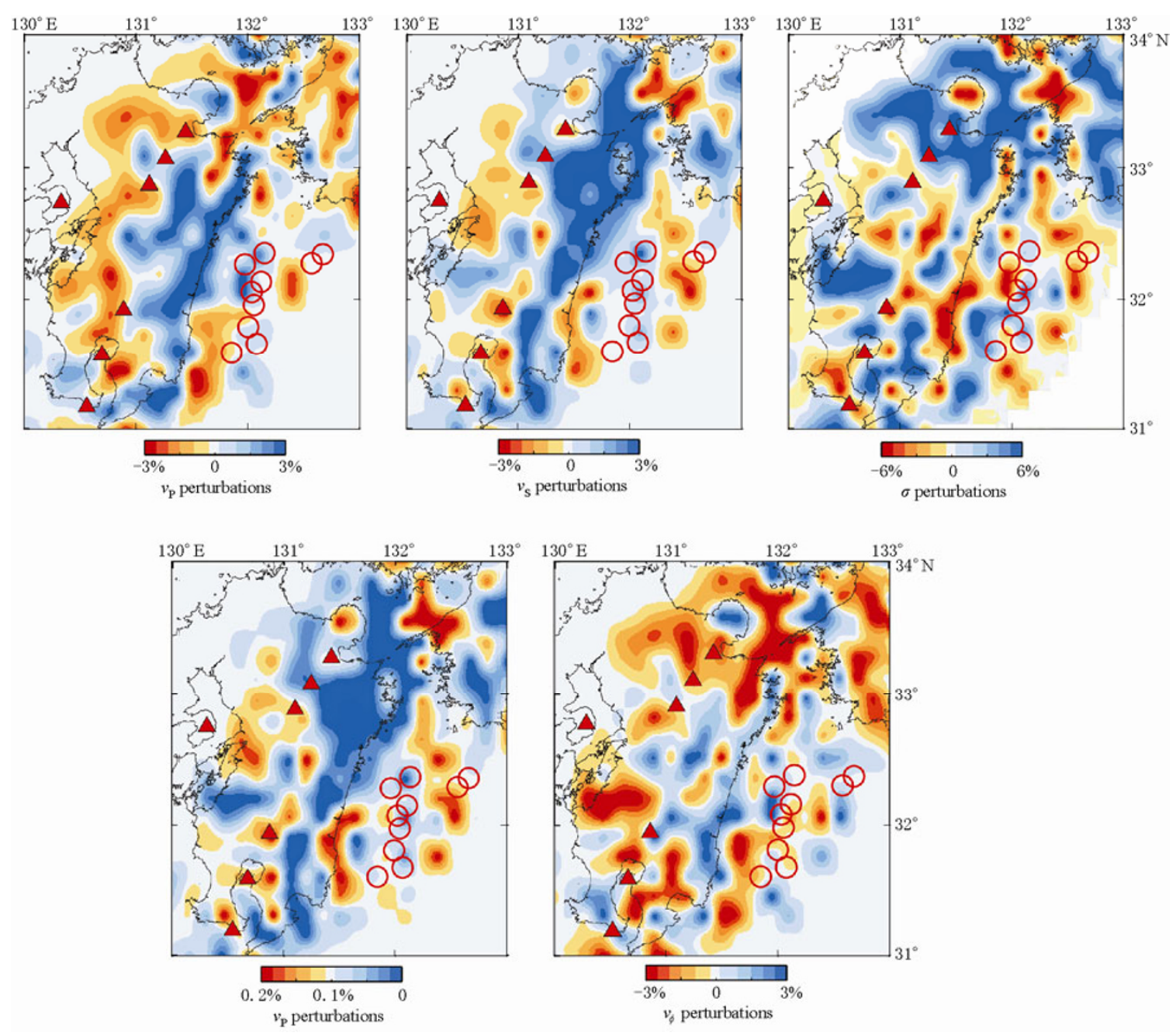

Figure 5 P-wave, S-wave, Poisson's ratio, crack-density and bulk sound velocity images along the upper boundary of the subducting Philippine Sea slab in Kyushu. Red triangles denote active volcanoes and red circles denote the large thrust earthquakes $(M>6.0)$ occurred during the period from 1923 to 1998 (Utsu, 1999; Yamaoka et al., 2002). The color scales of the velocity, Poisson's ratio, crack-density and bulk sound velocity are shown at the base of each map.

upper boundary. It is considered that the fluids are released from free pore water contained in the upper oceanic crust and sediments at shallow depth, because of the increasing temperature and compressional pressure, and/or are produced by the extensive dehydration of the subducting slab. We suggest that the low-velocity zones correspond to the weakly coupled or decoupled patches on the slab boundary (Matsuzawa et al., 2002; Zhao et al., 2002), which are caused by the presence of fluid-related anomalies.

\subsection{Slab dehydrationndainterplate coupling}

The subduction process is also found to be significant in illustrating the role of water and gas (e.g. carbon dioxide, sulphur dioxide) or fluids by influencing the thermo-petrological model of both cool and warm sub- duction metamorphism (Hacker et al., 2003a, b). The velocity images along with the Poisson's ratio, crack-density and bulk-sound velocity structures (Figures 3-5) show that considerable lateral heterogeneities exist on the upper boundary of the Pacific and the Philippine Sea slabs in the fore-arc regions, which might reflect serpentinization of the fore-arc mantle associated with dehydration of the subducting slab. The fore-arc mantle is probably aseismic because of the stable-sliding serpentinite hydrated by water that is expelled upward from the under-thrusting oceanic crust and sediments. Laboratory studies have indicated that serpentinite generally exhibits stable-sliding behavior (e.g., Reinen, 2000). Serpentinite is believed to exhibit stable-sliding behavior at the plate subducting rate, thus impeding rupture into the fore-arc 

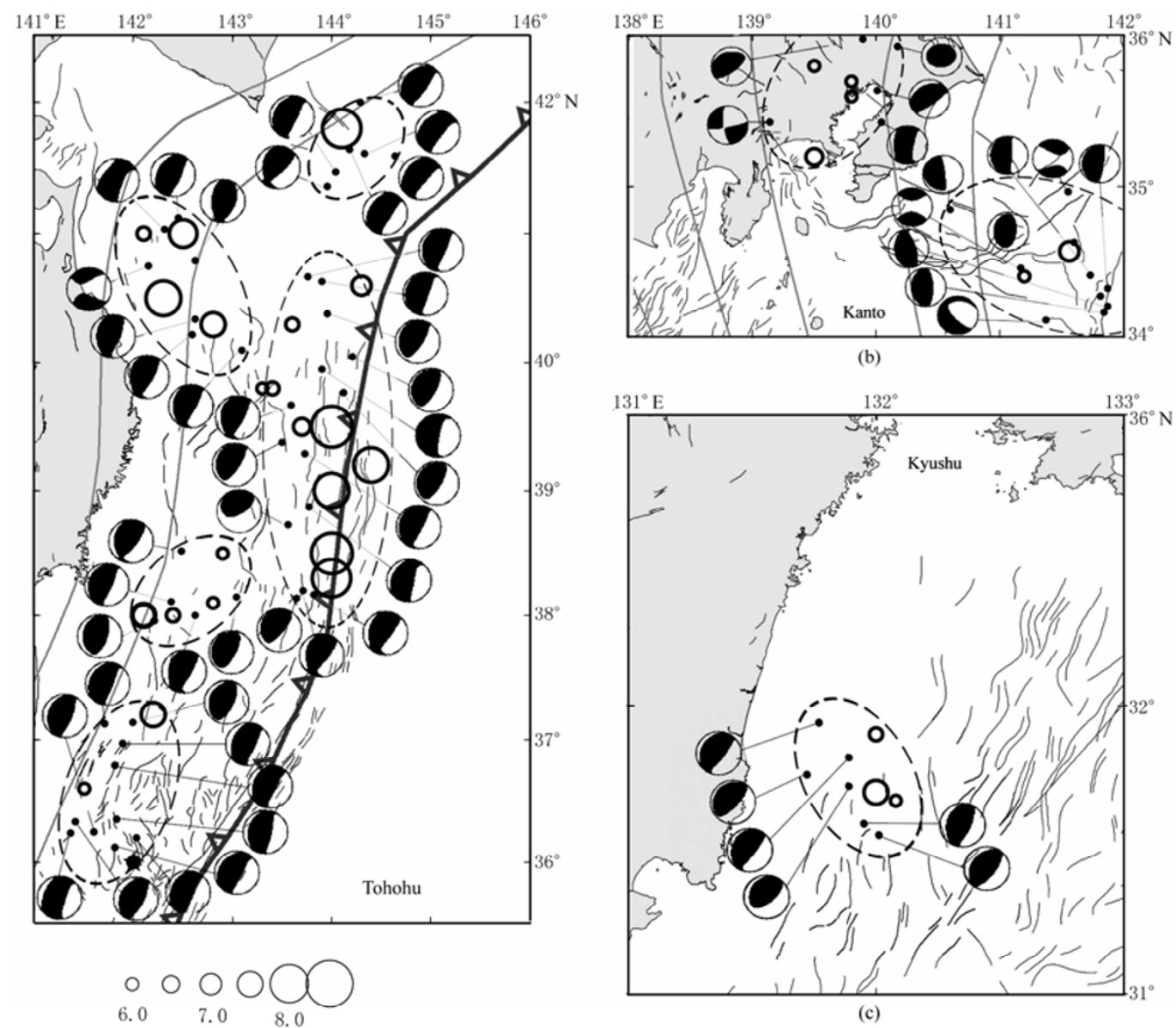

(b)

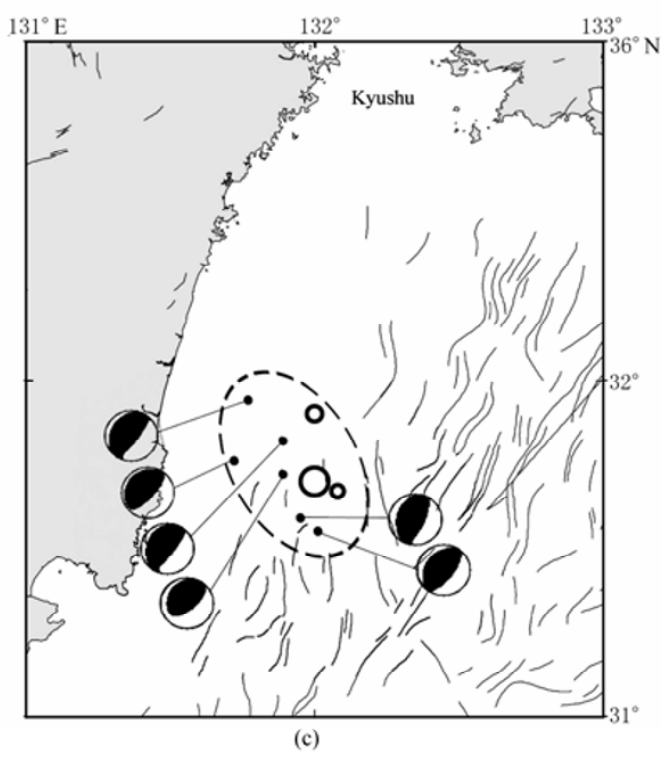

(a)

Figure 6 Focal mechanism of the thrust earthquakes occurred in the fore-arc regions of Northeast Japan (a), the Kanto district (b) and Kyushu (c). Open stars denote the large thrust earthquakes $\left(M_{\mathrm{b}}>6.0\right)$ during the period from 830 to 2007. Black dots present the earthquakes $(M>5.0)$ from 1970 to 2007. Gray thin lines indicate the active faults. The gray bold line shows the Japan Trench (a). Gray solid lines show the upper boundaries of the Pacific plate ( $a$ and $b$ ). The magnitude of the large thrust earthquakes is shown at the bottom.

mantle (Bostock et al., 2002). The mechanism for generating stable-sliding behavior in a subducting slab is the serpentinization of the mantle wedge. Water liberated by the dehydration reactions within the subducting plate might intrude into the overlying fore-arc mantle wedge, resulting in the formation of serpentine minerals and possibly other hydrous minerals, such as talc and brucite (Peacock and Hyndman, 1999). Because serpentinization will dramatically reduce the seismic velocity, the mechanical strength and density in the fore-arc mantle while increase the Poisson's ratio, magnetization and electrical conductivity (Hyndman and Peacock, 2003), the serpentinized fore-arc mantle is probably highly heterogeneous and some fluids escape to the surface. Such fluids will migrate into the overlain mantle and decrease the seismic velocity in the fore-arc mantle by the ser- pentinization process. If the fore-arc mantle is serpentinized, the pattern of convection will be altered in the mantle wedge because of the weak rheology, low seismic velocity and rock density. Such a proposal is evidenced from our estimated seismic velocity, Poisson's ratio and crack-density structures (Figures 3-5). Strong low-velocity and high Poison's ratio anomalies under the fore-arc regions along the upper slab boundaries are expected to correspond to the serpentinization of the corearc mantle associated with the slab dehydration (Figures 3-5). Therefore, it is believed that large volumes of aqueous fluids is released upwards by dehydration reactions in the subducting oceanic crust and sediments; the subduction of the oceanic lithosphere will then cool the overlying fore-arc mantle such that low-temperature hydrous serpentine minerals are stable 
in the fore-arc mantle.

Several researchers estimated the extent of hydration and serpentinization of mantle wedge for different subduction zones using laboratory experiments, such as Chile margin (serpentinization, $0-12 \%$; water, $0-3.6 \%$ by weight), central Japan (serpentinization, 30\%-40\%, water, $4 \%-5 \%$ by weight), SW Japan (serpentinization, $0-15 \%$, water, $0-2 \%$ by weight), Cascadia (serpentinization, $25 \%-30 \%$, water, $3 \%-4 \%$ by weight), and Costa Rica (serpentinization, $15 \%-25 \%$, water, $3 \%-4 \%$ by weight) (e.g., Kamiya and Kobayashi, 2000; Zhao et al., 1992; Hyndman and Peacock, 2003; Deshon et al., 2003; Seno, 2005). Serpentinized mantle wedge near the subducting Cocos plate in Costa Rica implies that rupture during large magnitude earthquakes may not initiate but may propagate along the oceanic slab/continental mantle interface making the downdip limit of the seismic zone beneath northern Costa Rica strain-rate dependent (Deshon et al., 2003). The crack-density and bulk-sound velocity images, calculated from the corresponding velocity models, indicate that the interplate coupling in Northeastern Japan is different from that under central and Southwestern Japan owing to differences between the tectonic backgrounds of the subduction system, such as the geological age, thermal regime and dipping angle of the oceanic plates. The geological age of the subducting Pacific plate under northeastern Japan is more than $140 \mathrm{Ma}$ with plate thickness of $80 \mathrm{~km}$, while the geological age of the Philippine Sea plate in southwest Japan is about $50 \mathrm{Ma}$ with plate thickness of $30 \mathrm{~km}$. The dipping angle is about $30^{\circ}$ of the Pacific plate in northeast Japan and about $60^{\circ}$ of the Philippine Sea plate in southwest Japan. The thermal-petrologic model predicts that the oceanic crust of the Philippine Sea plate under southwest Japan is $300^{\circ} \mathrm{C}-500^{\circ} \mathrm{C}$ which is warmer than that beneath Northeast Japan (Peacock and Wang, 1999). These features result in different coupling models of the Pacific plate in northeast Japan and the Philippine Sea plate in southwest Japan.

For the subducting slab, the down-dip limit of the great thrust earthquakes generally corresponds to the intersection of the thrust zone with the fore-arc mantle (Seno et al., 2001; Seno, 2005), which was explained by the distribution of aseismic hydrous minerals such as serpentinite (Peacock, 1990; Oleskevich et al., 1999; Hyndman et al., 1997). Our results show that large earthquakes that occurred along the PHS-Eurasian and the upper Pacific boundaries are located in areas with seismic velocities higher than that of surrounding areas (Figures 3-5), reflecting strongly coupled asperities. We conclude that the spatial distribution of large interplate earthquakes is possibly controlled by lateral heterogeneities, including strongly coupled sections (asperities) and weakly coupled or decoupled patches along the upper slab boundary due to the extensive dehydration process.

\section{Conclusions}

In this study some new features of the structural heterogeneities have been revealed from the 3-D seismic velocity, Poisson's ratio, crack-density and bulk-sound velocity images along the slab upper boundaries under the fore-arc regions of Japan from Hokkaido to Kyushu. The velocity structures together with other physical parameters exhibit strong lateral heterogeneities under the fore-arc regions of Japan from northeast to southwest. On the upper boundary of the subducting Pacific and the PHS slabs, 92\% large interplate earthquakes $\left(m_{\mathrm{b}}>7.5\right)$ are located at the high-velocity, low Poisson's ratio, high crack-density and high bulk-sound velocity zones, which may represent strong-coupled portions or asperities on the slab upper boundary. Few large interplate earthquakes occur in areas of low velocity, high Poisson's ratio, low crack-density and low bulk-sound velocity areas, representing decoupled areas associated with fore-arc mantle serpentinization caused by fluids from the slab dehydration. The lateral heterogeneities along the slab upper boundary may control the degree and spatial extent of the interplate seismic coupling and the rupture nucleation of the large thrust earthquakes. The crack-density and bulk-sound velocity images indicate that the interplate coupling varies from Tohoku-Hokkaido subduction zone to the regions of Kanto district region and southwest Japan owing to different conditions of the tectonic setting and the subducting slab. We consider that the features of the seismotectonics and interplate coupling are mainly attributed to the slab dehydration controlled by the plate geological ages, the dipping angle and temperature of the subducting slab, and the convergence of the plates. Our study suggests that fluid plays an important role on the interplate coupling and seismotectonics in the subduction zone.

Acknowledgements The author appreciate Prof. John Chen and two anonymous referees who provided thoughtful review comments which improved the manuscript. The waveform and arrival time data used in 
this work are downloaded from the Hi-net data center of Japan via Internet. Most of the figures were made using GMT (Wessel and Smith, 1998). This work was partially supported by the research grants of the National Natural Science Foundation of China (Nos.40872148 and 40974024) and the New Century Excellent Talents in University, Ministry of Education (NCET2009).

\section{References}

Bostock M G., Hyndman R D, Rondenay S and Peacock S M (2002). An inverted continental Moho and serpentinization of the forearc mantle. Nature 417: 536-538.

Deshon H R, Schwartz S Y, Biklek S L, Dorman L M, Gonzalez V, Protti J M, Dixon T H and Flueh E R (2003). Seismogenic zone structure of the southern middle American Trench, Costa Rica. J Geophys Res 108, doi 10.1029/2002JB002294.

Hacker B R, Abers G A and Peacock S M (2003a). Subduction factory 1 . theoretical mineralogy, densities, seismic wave speeds, and $\mathrm{H}_{2} \mathrm{O}$ contents. $J$ Geophys Res 108: 2 029, doi: 10.1029/2001JB001127.

Hacker B R, Peacock S M, Abers G A and Holloway S D (2003b). Subduction factory 2. Are intermediate-depth earthquakes in subducting slabs linked to metamorphic dehydration reactions? J Geophys Res 108: 2 030, doi: 10.1029/ 2001JB001129, 2003 b.

Hasegawa A, Horiuchi S and Umino N (1994). Seismic structure of the northeastern Japan convergent margin: A synthesis. $J$ Geophys Res 99: 22 195-22 311.

Hyndman R D, Yamano M and Oleskevich D A (1997). The seismogenic zone of subduction thrust faults. The Island Arc $\mathbf{6}$ 244-260.

Hyndman R D and Peacock S M (2003). Serpentinization of the forearc mantle. Earth Planet Sci Lett 212: 417-432.

Ishida M (1992). Geometry and relative motion of the Philippine Sea plate and Pacific plate beneath the Kanto-Tokai district, Japan. J Geophys Res 97: 489-513.

Iio Y, Sagiya T, Kobayashi Y and Shiozaki I (2002). Water-weakened lower crust and its role in the concentrated deformation in the Japanese Islands. Earth Planet Sci Lett 203: $245-253$.

Kamiya S and Kobayashi Y (2000). Seismological evidence for the existence of serpentinized wedge mantle. Geophys Res Lett 27: 819-822.

Kawakatsu H and Seno T (1983). Triple seismic zone and the regional variation of seismicity along the northern Honshu arc. $J$ Geophys Res 88: 4215-4230.

Kanamori H (1971). Seismological evidence for a lithosphere normal faulting the Sanriku earthquakes of 1933. Phys Earth Planet Inter 4: 289-300.

Kawasaki I, Asai Y and Tamura Y (2001). Space-time distribution of interplate moment release including slow earthquakes and seismogeodetic coupling in the Sanriku-oki region along the Japan trench. Tectonophysics 330: 267-283.

Kamata H and Kodama K (1999). Volcanic history and tectonics of the southwest Japan arcs. Isl Rac 8: 393-403.
Kennett B L N, Wdiyantoro S and van der Hilst R D (1998). Joint seismic tomography for bulk sound and shear wave speed in the Earth's mantle. J Geophys Res 103: 12 469-12 493.

Kennett B L N and Cummins P R (2005). The relationship of the seismic source and subduction zone structure for the 2004 December 26 Sumatra-Andaman earthquake. Earth Planet Sci Lett 239: 1-8.

Long M and Van der Hilst R D (2006). Shear wave splitting from local events beneath the Ryukyu Arc: Trench-parallel anisotropy in the mantle wedge. Phys Earth Planet Inter 155: 300-312.

Matsuzawa T, Igrashi T and Hasegawa A (2002). Characteristic small-earthquakes sequence off Sanriku, Northeastern Honshu, Japan. Geophys Res Lett 29(11): 1543, doi: 10.1029/ $2001 G L 014632$.

Mishra O P, Zhao D, Umino N and Hasegawa A (2003). Tomography of the northeast Japan forarc and its implications for interplate seismic coupling. Geophys Res Lett 30(16): 1850 , doi: 10. 1029/2003 GL017736.

Nakajima J, Matsuzawa T and Hasegawa A (2002). Moho depth variation in the central part of northeastern Japan estimated from reflected and converted waves. Phys Earth Planet Inter 130: 31-47.

Nakajima J and Hasegawa A (2007). Subduction of the Philippine Sea slab beneath southwestern Japan: Slab geometry and its relationship to arc magmatism. J Geophys Res 112: B08306, doi:10.1029/2006JB004770.

O'Connell R J and Budiansky B (1974). Seismic velocities in dry and saturated cracked solids. J Geophys Res 79: 5412-5 426.

Oleskevich D A, Hyndman R D and Wang K (1999). The updip and downdip limits to subduction earthquakes: Thermal and structure models of Cascadia, SW Japan, Alaska and Chile. $J$ Geophys Res 104: 14 965-14 991.

Peacock M S and Hyndman R D (1999). Hydrous minerals in the mantle wedge and the maximum depth of subduction thrust earthquakes. Geophys Res Lett 26: 2 517-2 520.

Peacock S M (1990). Fluid processes in subduction zones. Science 248: 329-337.

Peacock M S and Wang K (1999). Seismic consequences of warm versus cool subduction metamorphism: Example from southwest and northeast Japan. Science 286: 937-939.

Reinen L A (2000). Seismic and aseismic slip indicators in serpentinite gouge. Geology 28: 135-138.

Schmid C, van der Lee S and Giardini D (2006). Correlated shear and bulk moduli to $1400 \mathrm{~km}$ beneath the Mediterranean region. Phys Earth Planet Inter 159: 213-224.

Seno T, Zhao D, Kobayashi Y and Makamura M (2001). Dehydration in serpentinized slab mantle: Seismic evidence from southwest Japan. Earth Planets Space 53: 861-871.

Seno T (2005). Variation of downdip limit of the seismogenic zone near the Japanese islands: Implications for the serpentinization mechanism of the forearc mantle wedge. Earth Planet Sci Lett 231: 249-262.

Springer M and Forster A (1998). Heat flow density across the central Andean subduction zone. Tectonophyics 291: $123-139$. 
Umino N, Hasegawa A and Matsuzawa T (1995). sP depth phase at small epicentral distances and estimated subducting plate boundary Geophys J Int 120: 356-366.

Utsu T (1999). Seismic study: A comprehensive review. University of Tokyo Press, Tokyo, 769-829 (in Japanese).

Waldhauser F and Ellsworth W L (2000). A double-difference earthquake location algorithm: Method and application to the Northern Hayward Fault, California. Bull Seismol Soc Am 90: $1353-1368$.

Wang Z and Zhao D (2005). Seismic imaging of the entire arc of Tohoku and Hokkaido in Japan by using P-wave, S-wave and sP depth-phase data. Phys Earth Planet Inter 152: 144-162.

Wang $\mathrm{Z}$ and Zhao D (2006a). $v_{\mathrm{P}}$ and $v_{\mathrm{S}}$ tomography of Kyushu, Japan: New insight into arc magmatism and forearc seismotectonics. Phys Earth Planet Inter 157: 269-285.

Wang Z and Zhao D (2006b). Suboceanic earthquake location and seismic structure in the Kanto district, central Japan. Earth Planet Sci Lett 241: 789-803.

Wang Z and Zhao D (2006c). Seismic evidence for the influence of fluids on the 2005 west off Fukuoka prefecture earthquake in southwest Japan. Phys Earth Planet Inter 155: 313-324.

Wang Z, Zhao D, Mishra O P and Yamada A (2006). Lithospheric heterogeneity and its implications for the low-

frequency tremor in Southwest Japan. Earth Planet Sci Letts 251: $66-78$.

Wang Z, Huang R, Huang J and He Z (2008). P velocity and gradient images beneath the Okinawa Trough. Tectonophysics 455: $1-13$.
Wang Z, Zhao D, Huang R, Tang X and Mishra O P (2009). Structural heterogeneity in Northeast Japan and its implications for the genesis of the 2004 and 2007 Niigata earthquakes in Northeast Japan. Bull Seismol Soc Am 99(6): 3 355-3 373.

Wessel P and Smith W (1998). New improved version of the Generic Mapping Tools released. Eos 79: 579.

Yamaoka K, Churei M and Ando M (2002). Inland earthquakes precede the interplate earthquakes in Hyuga-nada, Kyushu, Japan. J Geogr 111: 185-191 (in Japanese with English abstrct).

Zhang H, Thurber C H, Shelly A, Ide S, Beroza C and Hasegawa A (2004). High-resolution subducting-slab beneath northern Honshu, Japan, revealed by double-difference tomography. Geology 32(4): 361-364.

Zhao D, Hasegawa A and Horiuchi S (1992). Tomographic imaging of $\mathrm{P}$ and $\mathrm{S}$ wave velocity structure beneath northeastern Japan. J Geophys Res 97: 19909-19928.

Zhao D, Mishra O P and Sanda R (2002). Influence of fluids and magma on earthquakes: Seismological evidence. Phys Earth Planet Int 132: 249-267.

Zhao D, Wang Z, Umino N and Hasegawa A (2007). Tomographic imaging outside a seismic network: Application to the northeast Japan arc. Bull Seismol Soc Am 97: 1 121-1 132.

Zhao D, Wang Z, Umino N and Hasegawa A (2009). Mapping the mantle wedge and interpolate thrust zone of the northeast Japan arc. Tectonophysics 467: 89-106. 